\title{
Comparing Corporate Cultural Profiles Using the Cultural Dimensions of Hofstede
}

\author{
Michael Demmler, Ricardo Ortiz Ayala, Alejandra Urbiola Solís* \\ University of Queretaro, Mexico \\ *Corresponding author: ricardoortizayala@gmail.com
}

\begin{abstract}
A functioning corporate culture is vital for economic success and a fundamental characteristic of every enterprise. The objective of the present paper is to analyze and compare the cultural profiles of the Mexican footwear manufacturing company Vogatti and the Mexican, but German-based, automotive supplier Novem Car Interior Design using the model of the cultural dimensions of Geert Hofstede. Hofstede describes general and organizational culture by using the following 6 cultural dimensions: power distance, individualism - collectivism, masculinity femininity, uncertainty avoidance, long term - short term orientation and indulgence - restraint. The present paper is based on a collective case study approach and uses a Likert scale questionnaire. Generally, the two enterprises show remarkably different corporate cultural profiles in comparison to the original results of the Hofstede study for the Mexican society. Moreover, significant differences, due to different corporate characteristics, can be identified within the comparison of the two enterprises.
\end{abstract}

Keywords: national culture, organizational culture, Hofstede model, collective case study

Cite This Article: Michael Demmler, Ricardo Ortiz Ayala, and Alejandra Urbiola Solís, "Comparing Corporate Cultural Profiles Using the Cultural Dimensions of Hofstede." Journal of Business and Management Sciences, vol. 6, no. 2 (2018): 28-35. doi: 10.12691/jbms-6-2-1.

\section{Introduction}

General culture and organizational culture are fundamental characteristics of every enterprise and society. Still nowadays the most popular and most commonly used model to operationalize culture is the one of Dutch social psychologist Geert Hofstede. The model differentiates in the following 6 cultural dimensions: power distance, individualism - collectivism, masculinity - femininity, uncertainty avoidance, long term - short term orientation and indulgence - restraint.

The following paper uses Hofstede's model of the cultural dimensions within a collective case study approach. A questionnaire is applied to the employees of two different enterprises located in Mexico. The first company is a $100 \%$ Mexican footwear manufacturer named Vogatti S.A. de C.V. The second enterprise (Novem Car Interior Design S.A. de C.V.) is the Mexican subsidiary of the German automotive supplier Novem $\mathrm{GmbH}$. The present paper has the following research objective: Analyze and compare the cultural profiles of the Mexican footwear manufacturing company Vogatti and the German-based automotive supplier Novem Car Interior Design using the model of the cultural dimensions of Hofstede.

In general, the two enterprises show remarkably different values in their cultural dimensions in comparison to the original results of the Hofstede study for the Mexican culture. This is especially true for the dimensions power distance, masculinity-femininity and long term - short term orientation. Furthermore, significant differences, that are most apparent for the dimensions uncertainty avoidance, masculinity - femininity, power distance and long term short term orientation, can be found comparing the two enterprises. Those differences can be explained by varying company characteristics such as different businesses, enterprise sizes, enterprise histories and educational levels of the coworkers. Moreover, different cultural backgrounds of the enterprises (100\% independent Mexican enterprise vs. Mexican subsidiary of a German parent company) might influence the results.

The remainder of the paper is organized as follows: The subsequent chapter presents a literature review of the Hofstede model including definitions, original results for Mexico and Germany as well as criticism of the model. The third chapter briefly outlines the methodological approach used by the current paper before results are presented and interpreted in the fourth section. The paper closes with some concluding remarks.

\section{Literature Review}

\subsection{Culture and the Model of Cultural Dimensions of Geert Hofstede}

According to Hofstede [1] culture is the total sum of beliefs, rules, techniques, institutions, and artifacts that characterize human populations or put simply the collective programming of the mind. This implies that people share some kind of universal and collective set of values and the more individual part depends on aspects 
such as region, religion or family influence. In the article no. 1 of the UNESCO Universal Declaration on Cultural Diversity, culture is considered as a source of interchange, innovation and creativity. Also, it is considered patrimony of humanity [2]. In general, every country possesses cultural aspects where some are similar to other nations and some are very particular. In the era of globalization where the importance of traditional barriers such as time and space diminishes, business internationalization is a natural consequence of the economic system. Nowadays, it is common that companies have employees of several nationalities, a heterogenic group of people with different values, behaviors and cultural roots. Depending on the circumstances that a company is living, culture emerges and constitutes a dynamic system of intangible concepts like for example intercultural relations, perceptions, verbal and nonverbal codes. All of these concepts lead to a self-sustaining behavioral pattern that determines how things are done [3].

The Dutch scholar Geert Hofstede defines culture in his model by the following 6 different cultural dimensions: power distance, individualism - collectivism, masculinity femininity, uncertainty avoidance, long term - short term orientation and indulgence - restraint [4]. The original study of Hofstede dates back to the years 1967 to 1973 as he applied thousands of questionnaires to the workforce of
IBM taking into account the various international subsidiaries of the company. Like this, within his first study Hofstede [1] culturally characterizes the 40 biggest countries of the world - a number that according to Hofstede Insights [5] was expanded by various other studies as for example $[4,6,7]$ to currently 76 countries. Figure 1 shows the Model of the 6 Cultural Dimensions of Hofstede.

\subsection{Comparison of Mexico and Germany according to the Hofstede Model}

As can be seen in Table 1, the societies of Mexico and Germany show different cultural profiles. The people of Mexico can be characterized on average by high degrees of power distance, uncertainty avoidance and indulgence. Furthermore, they are collectivistic, short-term oriented and show a preference for masculine values. On the contrary, Germany can be characterized as a society a low degree in power distance and clear tendencies towards long-term orientation and restraint. Furthermore, German people tend more to individualism, masculinity and uncertainty avoidance. According to Hofstede Insights [8] the biggest cultural differences between Mexican and German people can be found for the dimensions of long term - short term orientation and indulgence - restraint. The smallest difference is evident in the dimension masculinity - femininity.

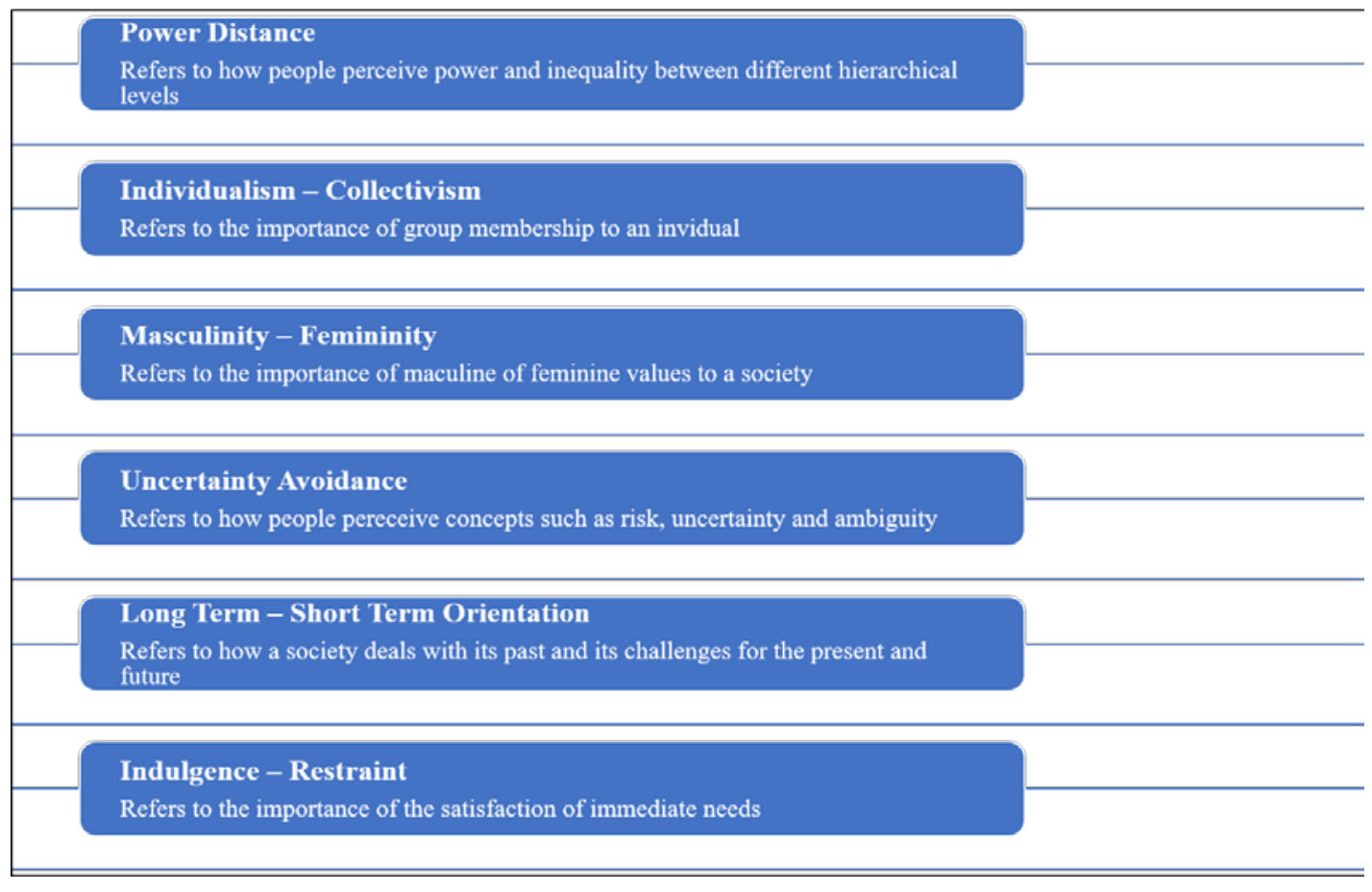

Figure 1. The 6 cultural dimensions of Hofstede [5]

Table 1. Comparison of the Mexican and German society within the Hofstede Model [8]

\begin{tabular}{|c|c|c|}
\hline Cultural Dimension & Mexico & Germany \\
\hline Power Distance & 81 & 67 \\
\hline Individualism - Collectivism & 30 & 66 \\
\hline Masculinity - Femininity & 69 & 65 \\
\hline Uncertainty Avoidance & 82 & 83 \\
\hline Long Term - Short Term Orientation & 24 & 40 \\
\hline Indulgence - Restraint & 97 & \\
\hline
\end{tabular}


Some further differences between the Mexican and the German culture can be found in the study of Rojanawisut et al. [9]:

Characteristics of Mexico:

- It is very common for Mexicans to work in a team-oriented manner in school and job.

- For Mexicans it is very important to address their superiors by their title.

- Mexicans show a very pronounced power distance in work relationships.

- After a mistake of a subordinate, superiors do not prefer to talk immediately to their employees, but some time later. It is also common to give people some clues or some indirect messages in order to help them to figure out their mistakes by themselves.

- Mexicans bosses prefer to talk about a problem in a passive way instead of arguing with their employees.

- Mexicans have a flexible concept of time. Although they always try to be on time, a delay of 5 to 10 minutes is considered to be still normal.

- In business relationships it is common to talk about something else (for example sports, personal things) before entering the business conversation.

- Mexicans do not follow a detailed organized planning process. They can be characterized as very flexible with reference to their planning and organization of work. Characteristics of Germany:

- A delay of 3 to 10 minutes depending on the circumstances of the meeting is still acceptable.

- Team work is generally preferred to individual work.

- Germans have a certain level of power distance. Contacts to superiors can be difficult depending on the position in the company or university hierarchy. The highest level of the hierarchy like the company's CEO or the university director can only be contacted if the topic to be discussed is very important and nobody else can deal with it.

- If somebody is wrong in a discussion she / he is usually directly criticized immediately.

- Within business meetings Germans come straight to the point and prefer not to talk about topics that are not related with the business.

- Within their working environment Germans make their proper plans and control that everything is going according to them.

\subsection{Criticism of the Hofstede Model}

Numerous existing studies as for example Jones [10], McSweeney, Brown \& Iliopoulou [11] and Schmitz \& Weber [12] express their critics referring the Hofstede concept. All of these critics emphasize the fact that culture is very complex what is not considered sufficiently by Hofstede. Some of the specific arguments against the Hofstede model are according to Abdullah et al. [13]:

- Relevancy

The survey is not a valid instrument to determine cultural differences and in some cases variables are more sensitive for one culture than for another.

- Cultural Homogeneity

Hofstede bases his study on the assessment of individuals. However, he then applies the results on the overall community.
- National Divisions

Culture is shared by different cultural groups that do not necessarily belong just to one country. Hence, nations are not a valid unit of analysis.

- Out-dated

The research results are outdated and do not reflect anymore that rapidly changing and globalized environment of today.

- One Company Approach

The research is just based on the analysis of one company, IBM. Hence, the results do not provide valid information regarding the culture of whole nations.

- Too Few Dimensions

Culture is too complex to be put into just few dimensions.

As a consequence of the critique of the model of the cultural dimensions of Hofstede, various other cultural models evolved. At this point, there should be mentioned the model of Trompenaars as an example. Trompenaars \& Hampden-Turner [14] differentiate between the following 7 cultural dimensions:

- Universalism vs. particularism

Importance of universal rules vs. adaption to particular circumstances regarding relationships

- Individualism vs. communitarianism

Represents the conflict of the interests of an individual vs. the interests of the group the individual belongs to

- Specific vs. diffuse

Refers to how people see life in general and their involvement in relationships

- Neutral vs. emotional

Reflects the importance of emotions in interpersonal relationships

- Achievement vs. ascription

Focuses on the assignment on personal status

- Sequential time vs. synchronous time

Represents the relative importance a group gives to time (past, present and future)

- Internal direction vs. outer direction

Explains if people base their actions based on themselves or their environment

Besides the multidimensional critiques on the Hofstede model it remained over the years until today the most commonly used theoretical and practical approach to characterize and quantify cultures. According to Søndergaard [15] Hofstede can be characterized as a pioneer and pathfinder in the area of cultural studies. Taking into account 61 replications of the Hofstede study Søndergaard [15] also found out that the majority of the replications confirm the Hofstede findings. Because of the existing arguments in favor of the Hofstede model and its evident acceptance within a wide range of research fields still nowadays also the present paper bases its methodological background on the Hofstede model.

\section{Methodology}

The present study formulates the subsequent research question: Which characteristics define the culture profiles of the Mexican footwear manufacturer Vogatti S.A. de C.V. and the German-based automotive supplier Novem Car Interior Design S.A. de C.V.? The research objective 
is to analyze and compare the cultural profiles of the Mexican footwear manufacturing company Vogatti and the German-based automotive supplier Novem Car Interior Design using the model of the cultural dimensions of Hofstede.

The independent Mexican company Vogatti S.A. de C.V. is located in the city of León (state of Guanajuato, Mexico) and started operations in November 1999. With a total of 79 coworkers Vogatti can be classified as a medium-sized enterprise. The company produces formal and casual footwear with a high degree of comfort for local Mexican shoe vendors. The large enterprise Novem Car Interior Design S.A. de C.V. employs about 1,000 workers. The company is the Mexican subsidiary of the German automotive supplier Novem GmbH and is located in the city of Querétaro (state of Querétaro, Mexico). Novem started operations in Mexico in 2011 and produces high-quality components for the car interior of international upper-class car manufacturers.

The current study is a collective case study applied to the two mentioned companies and uses a transactional descriptive design. A questionnaire was applied to the total of 79 workers of the company Vogatti and a total of 37 coworkers of the company Novem Car Interior Design. In general, the language used in the questionnaire was Spanish. However, to the few German coworkers of the company Novem, the questionnaire was provided in German. The questionnaire is based on the Likert scale and consists of a total of 60 questions (10 questions for each of the Hofstede dimensions) about culture in general and business culture. The data was processed using the quantitative analysis programs SPSS and MS Excel.

\section{Results and Discussion}

\subsection{Presentation of the Cultural Profile of the Mexican Footwear Manufacturing Company Vogatti}

The following subsection presents the cultural profile of the Mexican footwear company Vogatti. The present paper understands of a cultural profile a company's combination of its values of the different cultural dimensions of Hofstede. Table 2 and Figure 2 show the cultural profile of the company Vogatti. The results are based on the application of the outlined questionnaire to the total of 79 employees of the company. The presented results are averages of the employees' responses.

In the 2nd column of Table 2 ("Vogatti ( -2 to +2$)$ ") one can see for every cultural dimension its result for the company Vogatti expressed within the scale used in the questionnaire. Within this scale values between -2 (minimum possible value in a dimension) and +2 (maximum value in a dimension) are possible. For an easier interpretation of the company's results with the original Hofstede results the scale used within the paper's questionnaire is converted into Hofstede's original scale that is based on possible values between 0 and 100 for every dimension. This conversion of the results of the company Vogatti can be seen in the 3rd column of Table 2 ("Vogatti (0-100)"). The 4th column ("Mexican culture (0-100)") of the table presents the original results of Hofstede for the Mexican culture in general.

Table 2. Cultural profile of the company Vogatti in comparison with Hofstede's results

\begin{tabular}{|c|c|c|c|}
\hline Cultural Dimension & Vogatti (-2 to +2) & Vogatti (0-100) & 55.190 \\
\hline Power Distance & 0.208 & 50.918 & 41 \\
\hline Individualism - Collectivism & 0.037 .114 & 30 \\
\hline Masculinity - Femininity & -0.235 & 59.082 & 59.190 \\
\hline Uncertainty Avoidance & 0.363 & 82 \\
\hline Long Term - Short Term Orientation & 0.208 & 24 \\
\hline
\end{tabular}

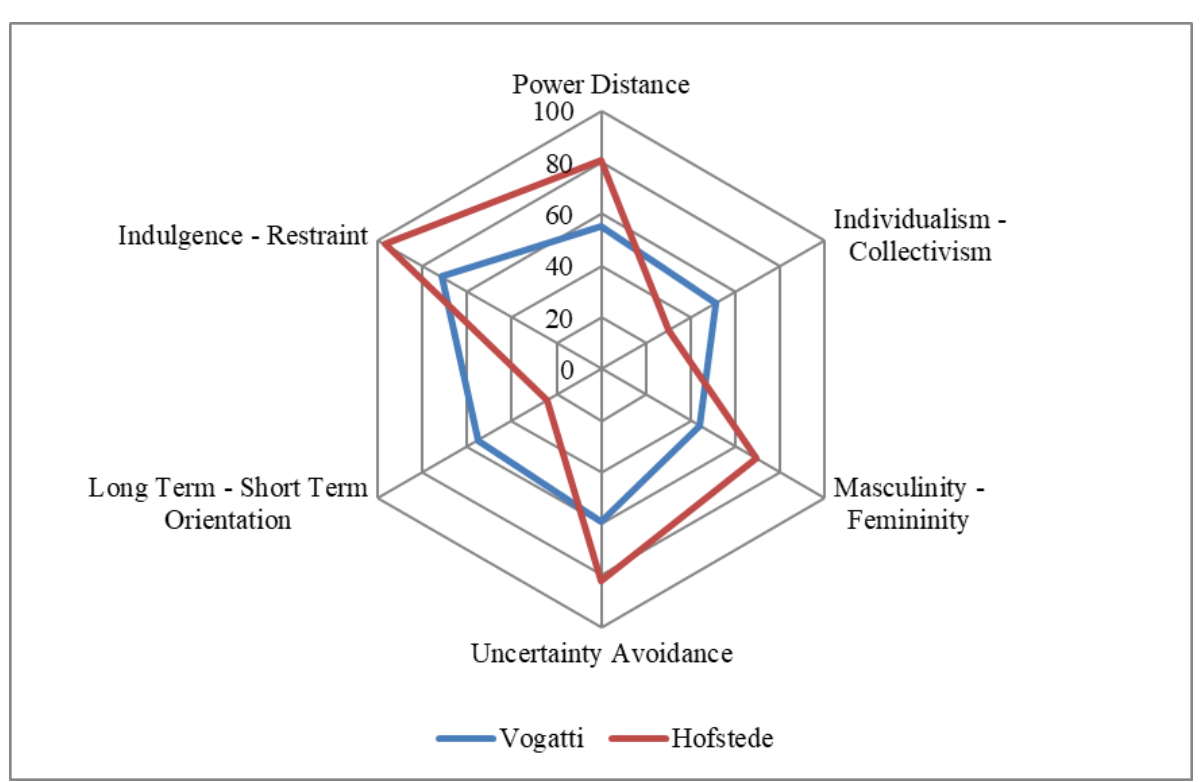

Figure 2. Cultural profile of the company Vogatti in comparison with Hofstede’s results 
Table 2 and Figure 2, that is simply a graphical approach to the columns 3 and 4 of Table 2, show the following results for the company Vogatti that are presented according to Ortiz Ayala, Demmler and Urbiola Solís [16]. The workers of the Mexican footwear manufacturer Vogatti show a value of 55.19 in the dimension of power distance what characterizes them as a group with a tendency to more instead of less power distance, i.e. distance between the different existing hierarchical levels. A deeper analysis of the individual questions of the questionnaire reveals that this power distance is more pronounced in the family context than in the working context. A comparison of Vogatti's value of 55.19 in this dimension with the value of the original Hofstede study for Mexico of 81 shows that Hofstede identifies the Mexican society as much more distant to power than the group of Mexican workers of the studied company. However, also for the company Vogatti the same tendency as Hofstede, i.e. a more instead of less pronounced power distance, can be confirmed for this cultural dimension.

Focusing on the dimension of individualism collectivism the company Vogatti presents a value of 50.92. Hence, there exists basically a balance between individualistic and collectivistic aspects. Referring to questions within the family context Vogatti's workers show a more individualistic tendency (the individual is more important than the collective) and within a working context a more collectivistic one (importance of teamwork, social events with colleagues). In this dimension, the original value of Hofstede for the Mexican culture is 30 what implies a stronger collectivism. Clearly contrary to Hofstede's results are the answers of the company's workers to the questions of the dimension masculinity -femininity. Vogatti shows a value of 44.11 in this dimension in comparison to 69 in the Hofstede study. This implies, that in contrast to the, according to Hofstede, more masculine Mexican culture the workers of Vogatti share on average more feminine values as for example care, preservation of others, consensus and corporation in the areas of work and family.

With a value of 59.08 the Mexican footwear company confirms the original result of Hofstede of 82 for the dimension of uncertainty avoidance. Thus, the two studies characterize their Mexican respondents as averse to uncertainty with a generally perceived uncomfortableness in situations that imply uncertainty, risk or ambiguity. A different result for the company Vogatti (55.19) in comparison to the original Hofstede study (24) is found again in the dimension long term - short term orientation. Hofstede identifies the Mexican society as relatively strong short term oriented. However, the 79 workers of the analyzed company show on average a slight tendency towards long term orientation that becomes apparent for example in their will to save for their pension or possible future expenditures and their aversion to credit. Referring to the last dimension of indulgence - restraint Vogatti's workers (value: 71.61) show the same tendency towards indulgence as Hofstede's original study of the Mexican culture (value: 97) as according to their answers to the questionnaire they assign a strong importance to concepts such as enjoying life and a healthy balance between working and leisure time.

As a summary, the group of Vogatti's employees show a more balanced cultural profile than the original results of Hofstede for the Mexican society. This means, that the results for each dimension for the studied company are closer to a balanced value of 50 and Hofstede, in contrast, presents more extreme values for the Mexican culture in general. Furthermore, the present study confirms the tendencies of Hofstede for the dimensions power distance, uncertainty avoidance and indulgence - restraint. However, different or opposite results are found for the dimensions individualism - collectivism, masculinity femininity and long term - short term orientation.

\subsection{Presentation of the Cultural Profile of the German Company Novem Car Interior Design}

The following subsection of the paper presents the cultural profile of the company Novem Car Interior Design that can be seen in Table 3 and Figure 3 using the same scheme as in the presentation of the footwear manufacturer Vogatti in the previous subsection. The results for the company Novem Car Interior Design are based on the application of the questionnaire on 37 individuals. As the company employs about 1,000 workers, 37 individuals appear to be just a small portion. The small number of participants is due to a limited access provided by the enterprise. However, we are confident that the analyzed group shows representative characteristics as different variables such as gender, age, hierarchical levels and nationality are combined in an adequate way.

As can be seen in Table 3 and Figure 3, the company Novem Car Interior Design shows a different cultural profile in comparison to the results of the original Hofstede study for the Mexican culture. The paper compares the company results with Hofstede's results for Mexico (and not for Germany) because even though Novem Car Interior Design is the Mexican subsidiary of a German enterprise their location and market are Mexico and the vast majority of their coworkers are Mexican.

Table 3. Cultural profile of the company Novem in comparison with Hofstede's results

\begin{tabular}{|c|c|c|c|}
\hline Cultural Dimension & Novem (-2 to +2) & Novem (0-100) & 45.676 \\
\hline Power Distance & -0.173 & 43.987 & 31.892 \\
\hline Individualism - Collectivism & -0.241 & 30 \\
\hline Masculinity - Femininity & -0.724 & 42.973 & 47.072 \\
\hline Uncertainty Avoidance & -0.281 & 82 \\
\hline Long Term - Short Term Orientation & -0.119 & 72.770 \\
\hline
\end{tabular}




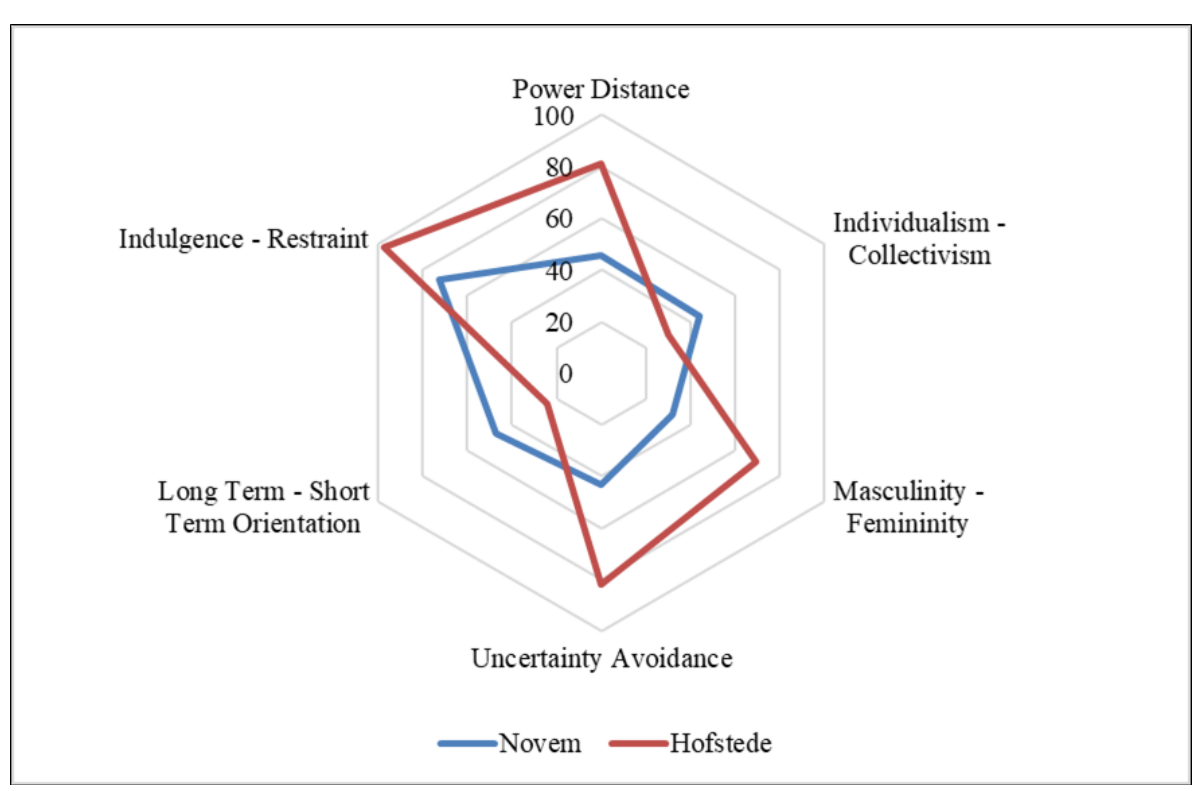

Figure 3. Cultural profile of the company Novem in comparison with Hofstede's results

Referring to the dimension of power distance the company shows a value of 45.68. Hence, Novem's employees can be characterized on average as less distant to power. Similar to the company Vogatti, this less pronounced power distance is even stronger within the working context in comparison to a family context. The company workers, for instance, answer that they feel comfortable with frequent contact with and feedback from their superiors. Furthermore, they have on average the confidence to question their superiors' decisions if this would be for the good of the company. The company's result for the analyzed dimension differs significantly from the Hofstede result for the Mexican culture of 81 . Hofstede characterizes the Mexican society as strongly distant to power. As was already mentioned, Novem Car Interior Design can be described by relatively few power distance.

The 2nd dimension is the one of individualism collectivism. With a result of 43.99 the coworkers of the company show on average a collectivistic tendency that is similar, but not that strong, to the collectivistic characterization of the Mexican society by Hofstede (value: 30). This collectivistic tendency of Novem's employees is apparent for example in the importance they give to group work and social events with the company. With 31.89 in the dimension of masculinity - femininity the company Novem Car Interior Design shows a stronger focus on feminine values (e.g. importance of gender equality, collaboration, democratic leadership) than on masculine values. This result is once again in contrast to the definition of the Mexican society as rather masculine by Hofstede (value: 69).

Contrary to the original study of Hofstede (value: 82) is also Novem's result in the dimension of uncertainty avoidance (42.97). On average the company's workers perceive situations characterized by uncertainty, risk or ambiguity less problematic in general. For example, the majority of them prefers a varied work instead of a monotone one. However, there are also few examples where they indeed show a negative attitude towards uncertainty (e.g. fixed-term contracts). The result of the company in the dimension of long term - short term orientation is 47.07. Thus, Novem's coworkers can be characterized as slightly short - term oriented, what they express, for example, with the importance they give to traditions and the past. However, they also show characteristics of long-term orientation (general aversion to credit, wish to safe for unknown future expenditures and retirement). With a value of 24 also Hofstede defines the Mexican society as short-term oriented. As it is the case for the company Vogatti, also Novem Car Interior Design shows it's highest value in the last dimension, indulgence - restraint. With a result of 72.77 the company workers show a significant tendency towards indulgence as the give strong importance to, for instance, family and leisure time as well as sports in comparison to working time. This tendency, but stronger, is also shown by the original study of Mexico by Hofstede (value: 97).

As a summary, also the company Novem Car Interior Design shows a more balanced cultural profile than the Hofstede profile for the Mexican society. Within the dimensions of individualism - collectivism, long term short term orientation and indulgence - restraint the present study shows similar results to Hofstede for the company Novem. Within the dimensions power distance, masculinity - femininity and uncertainty avoidance the results are opposite.

\subsection{Comparison of the Cultural Profiles of the Companies Vogatti and Novem}

The following Table 4 and Figure 4 compare the cultural profiles of the two presented enterprises, Vogatti and Novem Car Interior Design.

A profound and dimension-based analysis of Table 4 and Figure 4 comes to the following conclusions:

- Power Distance: With 55.19 the company Vogatti shows a more pronounced power distance than the company Novem (value: 45.68). Hence, defining 50 as an equilibrium, the coworkers of Vogatti can be identified as a rather power distant group and the ones of Novem as rather non-distant to power, i.e. the differences between hierarchical levels are more apparent in Vogatti than in Novem. Both enterprises 
show a value below the result of 81 of the original Hofstede study for Mexico.

- Individualism - Collectivism: The result of Novem (43.99) is below the result of Vogatti (50.92) for this dimension. This means that the employees of Novem Car Interior Design give more importance to collectivistic concepts and attitudes than their Vogatti counterparts. While Novem shows a clear tendency towards collectivism, Vogatti's workers seem to be balanced between individualistic and collectivistic influences. Both enterprises show a value above the original Hofstede result (30).

- Masculinity - Femininity: In comparison to the Hofstede result for Mexico (69), which implies a strong tendency towards masculine values and patterns, the companies Vogatti and Novems show opposite results. The workers of the two enterprises assign more importance to feminine values - a tendency that is, however, stronger for Novem (31.89) than for Vogatti (44.11).

- Uncertainty avoidance: Within this dimension both enterprises show a lower result than the value of 82 of the original Hofstede study. With a value of 59.08 Vogatti's coworkers seem to have more difficulties while dealing with situations influenced by uncertainty, risk and ambiguity than the employees of Novem (42.97).

- Long term - short term orientation: With a value of
55.19 Vogatti's workers are rather long term oriented in comparison to Novem's rather short term oriented staff (47.07). However, both enterprises are above the value of 24 of Hofstede who identifies the Mexican society clearly short term oriented.

- Indulgence - restraint: Both enterprises, Novem (72.77) even slightly more than Vogatti (71.61), show clear tendencies towards indulgence what implies strongly important attitudes towards enjoying life. However, the extreme value of 97 of Hofstede is not confirmed by the two enterprises.

As can be seen the cultural profiles of the two companies are much more similar to each other than the comparison of each enterprise with the original cultural profile for Mexico of Hofstede. Here it was already mentioned for the two enterprises that they are characterized by a much more balanced cultural profile than the Mexican Hofstede profile with more extreme results. Based on this, it is at least questionable if the original Hofstede results still represent correctly the currently existing cultural tendencies within the Mexican society. It is not clear in which year the original results of Hofstede for the Mexican culture were obtained. It is possible that they are still the results of the first Hofstede study of the year 1978. In this case, the present study would contribute to an updating of the characteristics of the Mexican culture and would show changing trends in time [16].

Table 4. Comparison of the cultural profiles of Vogatti and Novem

\begin{tabular}{|c|c|c|}
\hline Cultural Dimension & Vogatti (0-100) & Novem (0-100) \\
\hline Power Distance & 55.190 & 45.676 \\
\hline Individualism - Collectivism & 50.918 & 31.987 \\
\hline Masculinity - Femininity & 44.114 & 42.973 \\
\hline Uncertainty Avoidance & 59.082 & 47.072 \\
\hline Long Term - Short Term Orientation & 55.190 & 72.770 \\
\hline Indulgence - Restraint & 71.614 & \\
\hline
\end{tabular}

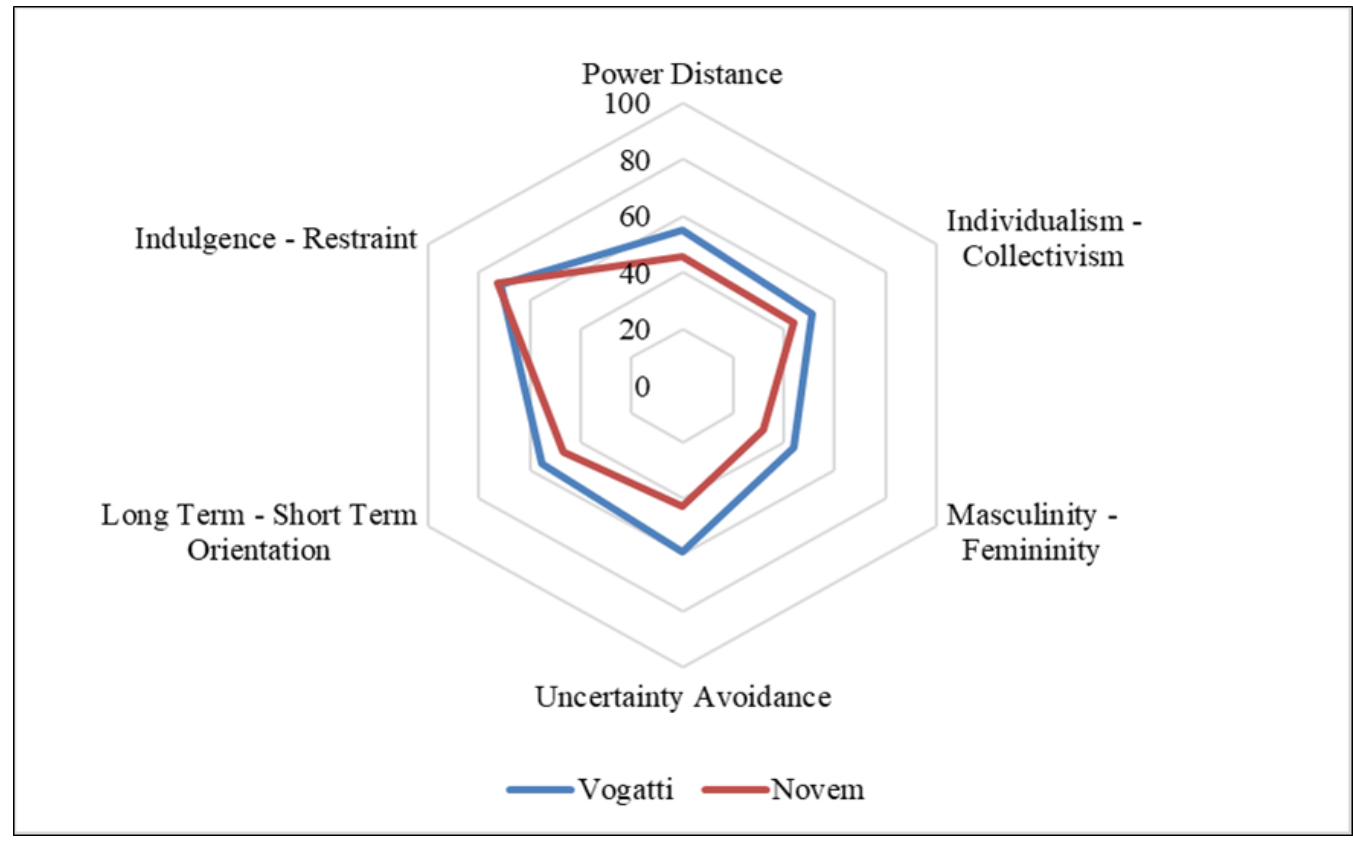

Figure 4. Comparison of the cultural profiles of Vogatti and Novem 
However, there exist also clear cultural differences between the two companies that are most apparent in the dimensions uncertainty avoidance, masculinity femininity, power distance and long term - short term orientation. Possible explanations of these gaps can be found in different variables as for example varying businesses, different enterprise sizes, different enterprise histories or different educational levels of the coworkers. Furthermore, the fact that the company Novem Car Interior Design is the Mexican subsidiary of a German enterprise might have a significant influence. This means that it is possible that the Mexican coworkers adapt over time to a corporate culture that is not classical Mexican but shows German influences. Moreover, within the application of the questionnaire also some German expatriates of the company were taken into account. Hence, it is possible that these persons change to some degree the overall cultural profile of the company.

\section{Conclusion}

The research objective of the current paper was to analyze and compare the cultural profiles of the Mexican footwear manufacturing company Vogatti and the German-based automotive supplier Novem Car Interior Design using the model of the cultural dimensions of Hofstede. The model of the cultural dimensions of Geert Hofstede is still nowadays the most commonly used approach to quantify general and organizational culture using the following 6 dimensions: power distance, individualism - collectivism, masculinity - femininity, uncertainty avoidance, long term - short term orientation and indulgence - restraint. In the form of a collective case study approach the current paper used a Likert scale questionnaire containing a total of 60 questions - 10 for each cultural dimension. In the footwear manufacturing company Vogatti a total of 79 workers responded to the questionnaire and in the enterprise Novem Car Interior Design a total of 37 subjects.

The main results of the paper are as follows: The two analyzed companies show more balanced cultural profiles than the original results of the Hofstede study for the Mexican society. This means, that the results for each dimension for the studied enterprises are closer to a balanced value of 50 and Hofstede, in contrast, presents more extreme values for the Mexican culture in general. However, also clear cultural differences between the companies Vogatti and Novem can be found for example in the dimensions uncertainty avoidance, masculinity femininity, power distance and long term - short term orientation. Possible explanations of these cultural gaps can be identified in different variables as for example varying businesses, different enterprise sizes, different enterprise histories or different educational levels of the employees. Furthermore, the fact that the company
Novem Car Interior Design is the Mexican subsidiary of a German enterprise might have a significant influence. This means that it is possible that the mainly Mexican employees adapt over time to a corporate culture that is influenced by German values and concepts.

\section{References}

[1] Hofstede, G. (1980). Culture's Consequences: International Differences in Work-Related Values. Beverly Hills: Sage Publications.

[2] UNESCO (2001) UNESCO Universal Declaration on Cultural Diversity, URL:

http://portal.unesco.org/en/ev.php-

URL_ID=13179\&URL_DO=DO_TOPIC\&URL_SECTION=201. html.

[3] Hofstede, G. (2001) Culture's Consequences: Comparing Values, Behaviors, Institutions, and Organizations Across Nations. 2nd ed. Thousand Oaks, London, New Delhi: Sage Publications.

[4] Katzenbach, J., Oelschlegel, C. \& Thomas, J. (2016) 10 Principles of Organizational Culture. URL:

https://www.strategy-business.com/feature/10-Principles-ofOrganizational-Culture.

[5] Hofstede Insights (2018a) National Culture. URL: https://www.hofstede-insights.com/models/national-culture/.

[6] Minkov, M. \& Hofstede, G. (2014) A replication of Hofstede’s uncertainty avoidance dimension across nationally representative samples from Europe. International Journal of Cross Cultural Management, 14, 161-171.

[7] Rotondo Fernandez, D., Carlson, D., Stepina, L. \& Nicholson, J. (1997) Hofstede's Country Classification 25 Years Later. Journal of Social Psychology, 137 (1), 43-54.

[8] Hofstede Insights (2018b) Country Comparison. URL: https://www.hofstede-insights.com/countrycomparison/germany,mexico/.

[9] Rojanawisut, B., Lo, C. X., Vernier, J., Gálvez Hernández, O. \& Beyer, J. P. (2010) Business between Germany and Mexico Cultural Analysis and Comparison from a Business Perspective. URL:

https://www.iei.liu.se/indek/utbildning/industriellmarknadsforing/teim03/file-archive2015/1.658320/group5_GermanyVsLatinAmerica.pdf.

[10] Jones, M. (2007) Hofstede - Culturally Cuestionable?, Oxford Business and Economics Conference, Oxford, UK, 24-26 June, 2007.

[11] McSweeney, B., Brown, D. \& Iliopoulou, S. (2016) Claiming Too Much, Delivering Too Little - Testing Some of Hofstede's Generalisations. Irish Journal of Management, 35 (1), 34-57.

[12] Schmitz, L. \& Weber, W. (2014) Are Hofstede's Dimensions Valid? A Test for Measurement Invariance of Uncertainty Avoidance. Interculture Journal, 13 (22), 11-26.

[13] Abdullah Shaiq, H. M., Sufyan Khalid, H. M., Akram, A. \& Ali, B (2011). Why not everybody loves Hofstede? What are the alternative approaches to study of culture? European Journal of Business and Management, 3 (6), 101-111.

[14] Trompenaars, F. \& Hampden-Turner, C. (1997) Riding the Waves of Culture: Understanding Diversity in Global Business. McGrawHill.

[15] Søndergaard, M. (1994). Research Note: Hofstede's Consequences - A Study of Reviews, Citations and Replications, Organization Studies, 15 (3), 447-456.

[16] Ortiz Ayala, R., Demmler, M. \& Urbiola Solís, A. (2017) The Cultural Dimensions of Hofstede in the Mexican Footwear Manufacturing Company Vogatti. International Journal of Academic Research and Reflection, 5 (4), 73-86. 